\title{
Projeto de bancadas didáticas para laboratório de instalações elétricas
}

\author{
Project of didactic workbenches for laboratory of electrical installations
}

\author{
Angélico Loreto Teixeira ${ }^{1}$, Lucas Giuliani Scherer ${ }^{2}$ e Ana Alice Timm Gorretti ${ }^{3}$
}

${ }^{1}$ Universidade Federal de Santa Maria, Cachoeira do Sul, Brasil angelicoloretoteixeira@gmail.com

${ }^{2}$ Universidade Federal de Santa Maria, Cachoeira do Sul, Brasil lgscherer@gmail.com

${ }^{3}$ Universidade Federal de Santa Maria, Cachoeira do Sul, Brasil anagoretty_t@hotmail.com

\section{Resumo}

O alto custo na montagem de laboratórios para o ensino superior é um desafio quando existe contingenciamento de recursos. Uma alternativa para contornar o alto custo no desenvolvimento das estruturas básicas dos laboratórios de ensino, consiste no projeto e implementação das bancadas do laboratório, construidas com o auxílio de professores, técnicos e alunos da universidade. Nesse trabalho será abordado o projeto de bancadas didáticas para o laboratório de instalações elétricas, capazes de atender as mais variadas ementas, tanto de cursos como Engenharia Elétrica, Engenharia Civil, Arquitetura e Urbanismo, entre outros. Analisando pelo ponto de vista financeiro, percebe-se uma economia superior a 90\%, em comparação à bancadas didáticas comerciais existentes no mercado. Além disso, se for levado em conta o aspecto de ensino aprendizagem dos alunos, os beneficios são maiores, visto que a própria concepção, projeto e construção das bancadas representam uma importante forma de aprendizado prático. Além do mais, a bancada visa aumentar o grau de complexidade das tarefas se comparada aos equipamentos existentes no mercado, visto que engloba mais conceitos. Para aquisição dos materiais, sugerese o uso de recursos institucionais próprios ou parceria com empresas públicas e privadas.

Palavras-chave: Bancadas didáticas; Instalações elétricas; Aprendizado prático

\section{Abstract}

The high cost of assembling laboratories for higher education is a challenge when there is a contingency of resources. An alternative to overcome the high cost in the development of the basic structures of the teaching laboratories, is the designing and implementation of laboratory workbenches, built with the help of teachers, technicians and university students. In this work will be approached the project of didactic workbenches for the laboratory of electrical installations, capable of attending the most varied menus, as well as courses such as Electrical Engineering, Civil Engineering, Architecture and Urbanism, among others. Analyzing from a financial point of view, there is an economy above $90 \%$, compared to commercial didactic workbenches in market. In addition, taking into account the teaching-learning aspect of the students, the benefits are greater, since the very design, design and construction of the benches represent an important form of practical learning. In addition, the workbench aims to increase the degree of complexity of the tasks compared to the existing equipment in the market, since it encompasses more concepts. For the acquisition of materials, it is suggested the use of institutional resources or partnership with public and private companies.

Keywords: Didactic workbenches; Electrical installations; Practical learning 


\section{Introdução}

Esse trabalho, aborda o projeto e implementação de bancadas didáticas para aplicação em atividades práticas de disciplinas relacionadas com o tema de instalações elétricas prediais e residenciais, em universidades públicas brasileiras, como alternativa às bancadas comerciais existentes no mercado. Atualmente, o país encontra-se em um período econômico delicado, com retração econômica e contingenciamento de gastos, principalmente em educação superior, por parte do governo federal. Portanto, fente às dificuldades apresentadas, essa obra propõe uma alternativa através do projeto e construção de bancadas didáticas, com custo reduzido em relação a produtos semelhantes existentes no mercado e com possibilidades maiores de aprendizagem por parte dos alunos. Além do mais, essa bancada aborda uma quantidade maior de conceitos técnicos, além do que, integra conceitos técnicos conforme são apresentados em situações reais do cotidiano. Como as tecnologias presentes no mercado estão sempre em evolução, se torna imprescindível não somente formar profissionais, como também, prepará-los e qualificá-los para atender as demandas da sociedade.

\section{Referencial Teórico}

Segundo Cervantes et. al (2008), devido às exigências atuais do mercado de trabalho, há uma preocupação crescente de professores e gestores de instituições educacionais no ensino correlato entre teoria e prática. Atualmente, essa capacidade de associar o ensino teórico-prático é o que possibilita um o estudante obter sucesso no mercado de trabalho dentro da área técnica.

Segundo Pandini et. al (2017), aulas que fazem uso de conhecimentos práticos, têm obtido cada vez mais relevância principalmente em cursos de engenharia, pois assim, levam os acadêmicos a aprenderem em situações reais. Por conseguinte, os fatores adversos que existem na atividade profissional, são apresentados aos acadêmicos exigindo uma postura de resolução de problemas, levando em conta as influências externas.

Conforme Cervantes (2008) e Figueiredo (2014), muitas vezes, as bancadas didáticas comercializadas no mercado, possuem valor agregado muito alto. Além disso, como o Brasil é um país com grandes extensões, a assistência técnica ao equipamento pode demandar muito tempo. Uma das maneiras para contornar esse problema, consiste na utilização dos conhecimentos adquiridos em sala de aula, para projeto e confecção de bancadas didáticas, diminuindo o custo final e eliminando gastos com assistência especializada.

Basicamente as instalações elétricas consistem do meio físico de interligação entre a fonte geradora e a(s) carga(s). Conforme a Norma Regulamentadora de Segurança em Instalações e Serviços em Eletricidade (2016) e a Norma Regulamentadora de Segurança do trabalho em máquinas e equipamentos (2018), essas bancadas devem atender a determinado requisitos previstos em normatizações. Além disso, deve ser robusto o suficiente, para suportar as intempéries e influências externas presentes no meio em que estão inseridas.

\section{Pocedimentos Metodológicos}

Inicialmente para desenvolver o projeto das bancadas didáticas, se definiu o tema instalações elétricas prediais e residenciais. Após, fez-se um levantamento das necessidades do mercado e os conceitos que devem ser aprendidos pelos alunos. Abordando conhecimentos que partem desde luminotécnica, automação residencial, divisão de circuitos elétricos, entre outros. Por conseguinte, se realizou uma pesquisa dos componentes elétricos, capazes de suprirem as necessidades e a forma como esses seriam dispostos e fixados na bancada. 


\section{Resultados e Discussão}

A bancada encontra-se em fase final de projeto e pronta para implementação. A ideia básica dessas bancadas, consiste na fixação de cinco chapas de MDF com $15 \mathrm{~mm}$ de espessura, 2,75 m de altura e 1,83 m de largura. Essas chapas podem ser alocadas em uma ou duas paredes de um laboratório, porém, como não ocupam muito espaço é possível que nesse mesmo laboratório, possa coexistir uma sala de aula ou até mesmo outro laboratório, como automação industrial ou eletrônica. Os componentes elétricos seriam presos nessas chapas, sendo que, em cada uma dessas seriam abordados conceitos diferentes e após, haveria o rodízio dos alunos entre as bancadas.

O layout das bancadas didáticas foi desenvolvido no software SketchUp, a partir do qual é possível visualizar o aspecto final dos projetos. A Figura 1 apresenta os resultados das modelagens das bancadas através do software em questão:

Figura 1 - Vistas do projeto de algumas bancadas didáticas, figura 1(a), figura 1(b), figura 1(c) e figura 1(d)

(a)

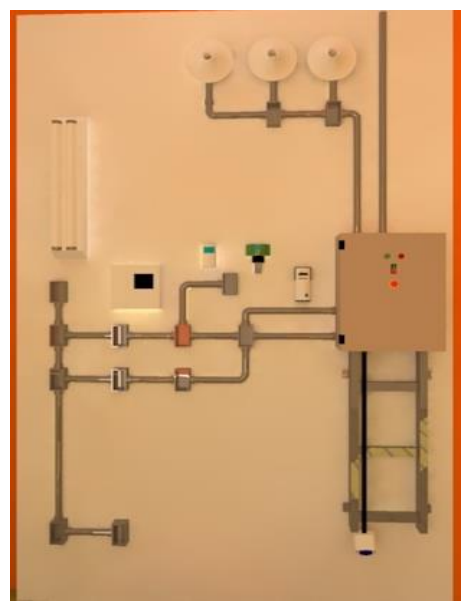

(c)

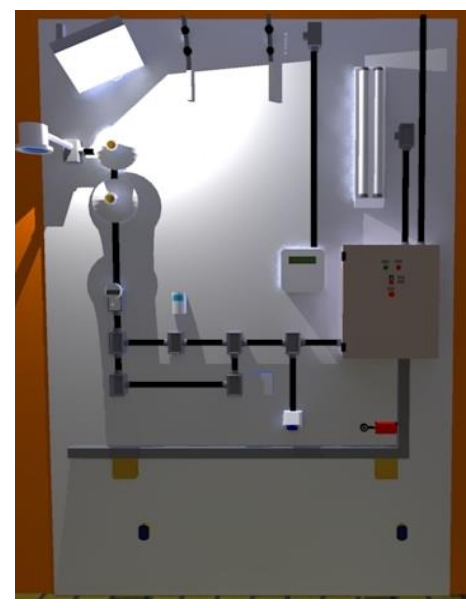

(b)

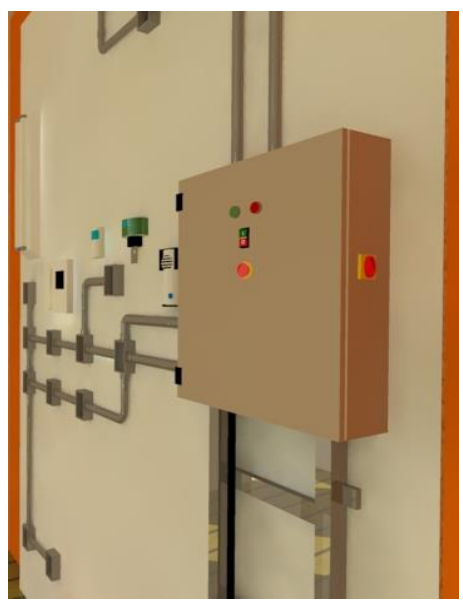

(d)

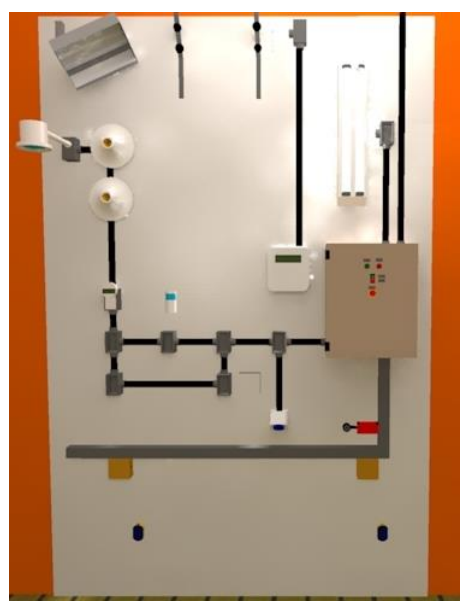

Como já mencionado, as bancadas didáticas possuem tarefas que possuem o objetivo de consolidar os conceitos teóricos aprendidos, através de atividades práticas e lúdicas visando o desenvolvimento completo das competências que o aluno necessita. A Tabela 1 apresenta uma proposta de tarefas a serem realizadas em uma das bancadas didáticas, sendo que ao lado o professor deve marcar SIM ou NÃO, como forma de avaliar se o aluno atingiu o objetivo da tarefa:

Esse projeto está em fase de implementação e ainda não foi finalizado, nem montado fisicamente, devido à limitação de recursos financeiros e principalmente espaço físico. Do ponto de vista econômico, constatou-se que uma bancada dessas ou 
equivalente, fornecida por algum grande fabricante, custe cerca de 100 mil reais cada módulo, sendo que ao se fazer uso dessa forma de montagem, o custo reduz para cerca de 10 mil reais, segundo cálculos prévios, ou seja, uma economia significativa. Acreditasse que como forma de melhoria, seja interessante adicionar fontes de energia renováveis como fotovoltaica ou eólica, além de monitoramento remoto e datalog das atividades que a bancada realiza. Assim, se agregam novos conceitos a tecnologias consolidadas

Tabela 1 - Lista de tarefas a serem realizadas pelos alunos nas bancadas didáticas

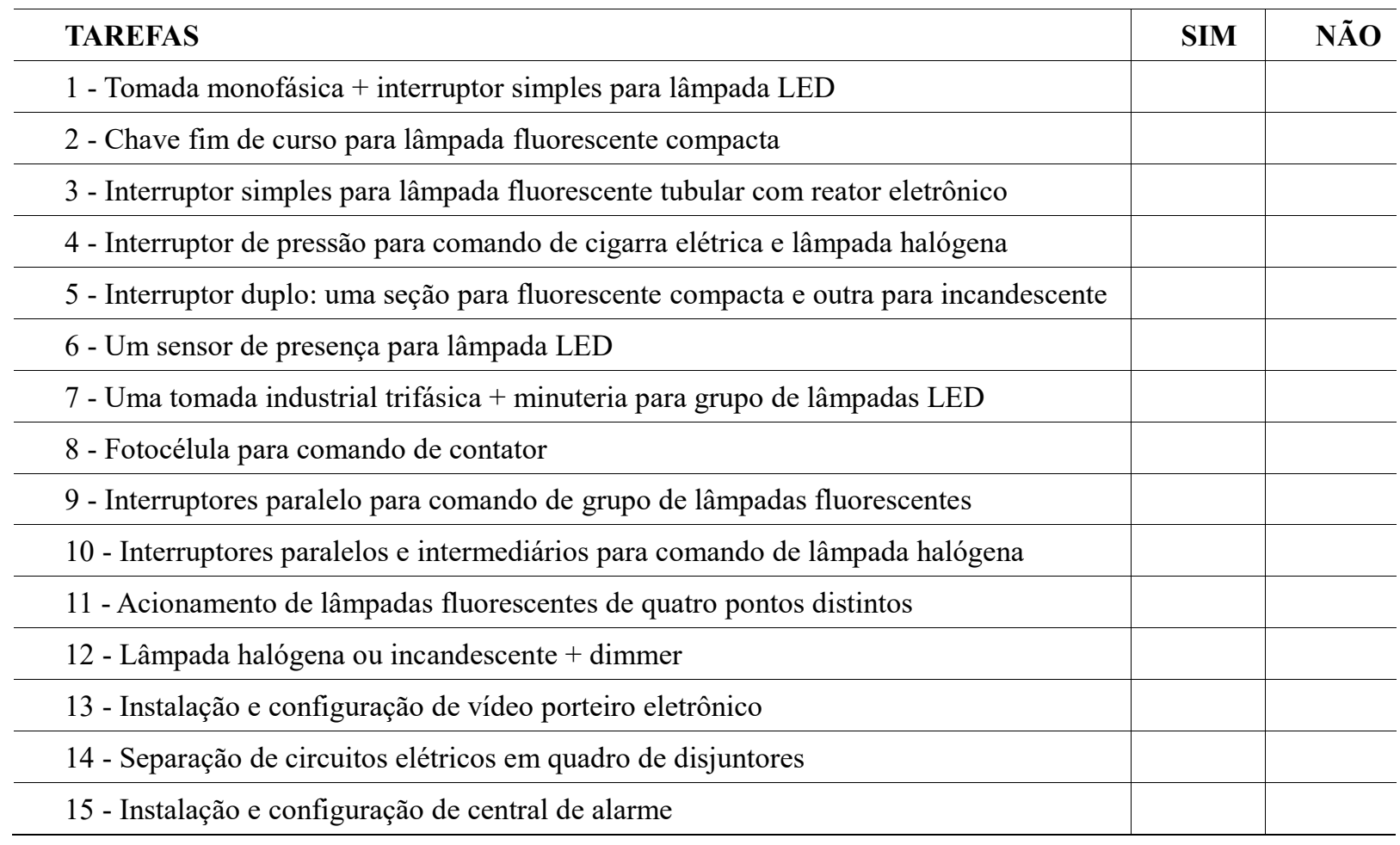

\section{Conclusões}

Esse trabalho abordou os procedimentos utilizados para o projeto e implementação de bancadas didáticas, para o ensino do conceito de instalações elétricas, sendo esse, pertinente aos mais diversos cursos de engenharia e arquitetura. Esse modelo de bancadas, também pode ser replicado em cursos técnicos, como método eficiente ao ensino. O projeto apresenta grande viabilidade econômica, visando tornar lúdicas as atividades de aprendizagem e servindo de estímulo para outras instituições replicarem ou até mesmo melhorarem essa ideia.

\section{Agradecimentos}

Agradecemos aos revisores, colaboradores e todas as pessoas que de alguma forma ou outra, contribuíram para a realização desse trabalho. Além disso, um agradecimento especial à Universidade Federal de Santa Maria, que tem nos propiciado meios para a concretização desse projeto. 


\section{Referências}

CERVANTES, S.G.S. Bancadas Didáticas para Sistemas de Automação Pneumática. COBENGE: Congresso Brasileiro de Educação em Engenharia, 2008. São Paulo (Brasil).

FIGUEIREDO, M. R. Construção e Validação de uma Bancada Didática de Impulso Hidrostático. COBENGE: Congresso Brasileiro de Educação em Engenharia, 2014. Juiz de Fora (Brasil).

MINISTÉRIO DO TRABALHO; Ministério do Trabalho e Emprego. Portaria N 326/18 - Norma Regulamentadora de Segurança do trabalho em máquinas e equipamentos. Brasília (Brasil): Ministério do Trabalho; 2018.

MINISTÉRIO DO TRABALHO; Ministério do Trabalho e Previdência Social. Portaria Nº 508/16 - Norma Regulamentadora de Segurança em instalações e serviços em eletricidade. Brasília (Brasil): Ministério do Trabalho; 2016.

PANDINI M.M., SPACEK A.D., NETO J. M., JUNIOR, O. H. A. Design of a Didatic Workbench of Industrial Automation Systems for Engineering Education. IEEE Latin America Transactions, vol. 15, no. 8, pp. 1384-1391, 2017. 